\title{
Health information, behavior change, and decision support for patients with type 2 diabetes: development of a tailored, preference-sensitive health communication application
}

\author{
This article was published in the following Dove Press journal: \\ Patient Preference and Adherence \\ 21 October 2013 \\ Number of times this article has been viewed
}

\section{Nina Weymann' \\ Martin Härter' \\ Frank Petrak ${ }^{2}$ \\ Jörg Dirmaier' \\ 'Department of Medical Psychology, University Medical Center Hamburg- Eppendorf, Hamburg, ${ }^{2}$ Clinic of Psychosomatic Medicine and Psychotherapy, LWL University Hospital, Ruhr-University Bochum, Bochum, Germany}

Purpose: Patient involvement in diabetes treatment such as shared decision-making and patient self-management has significant effects on clinical parameters. As a prerequisite for active involvement, patients need to be informed in an adequate and preference-sensitive way. Interactive Health Communication Applications (IHCAs) that combine web-based health information for patients with additional support offer the opportunity to reach great numbers of patients at low cost and provide them with high-quality information and support at the time, place, and learning speed they prefer. Still, web-based interventions often suffer from high attrition. Tailoring the intervention to patients' needs and preferences might reduce attrition and should thereby increase effectiveness. The purpose of this study was to develop a tailored IHCA offering evidence-based, preference-sensitive content and treatment decision support to patients with type 2 diabetes. The content was developed based on a needs assessment and two evidence-based treatment guidelines. The delivery format is a dialogue-based, tunneled design tailoring the content and tone of the dialogue to relevant patient characteristics (health literacy, attitudes toward self-care, and psychological barriers to insulin treatment). Both content and tailoring were revised by an interdisciplinary advisory committee.

Conclusion: The World Wide Web holds great potential for patient information and selfmanagement interventions. With the development and evaluation of a tailored IHCA, we complement face-to-face consultations of patients with their health care practitioners and make them more efficient and satisfying for both sides. Effects of the application are currently being tested within a randomized controlled trial.

Keywords: type 2 diabetes, interactive health communication application, development, Internet

\section{Introduction}

Patients, practitioners, scientists, and politicians have called for more patient involvement in the making of medical decisions as well as in the management of their diseases in order to reduce the burden on both sides. Patient involvement in diabetes management has been shown to reduce fasting blood glucose levels, $\mathrm{A}_{1 \mathrm{C}}$, and the need for

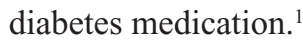

Two main aspects of patient involvement are self-management and shared decisionmaking (SDM). Self-management means that the patient successfully copes with the challenges of living with and treating diabetes. This may involve that the patient autonomously sets goals, identifies barriers and challenges, and monitors his or her health. ${ }^{2,3}$
Correspondence: Nina Weymann University Medical Center HamburgEppendorf, Department of Medical Psychology (W 26), Martinistraße 52, 20246 Hamburg, Germany

$\mathrm{Tel}+49040741057134$

Fax +4904074I054965

Emailn.weymann@uke.de 
SDM means ' (1) that at least two participants - physician and patient be involved; (2) that both parties share information; (3) that both parties take steps to build a consensus about the preferred treatment; and (4) that an agreement is reached on the treatment to implement.' ${ }^{4}$ Both for shared decision-making and for self-management, patients need to be informed about their disease, its course, and the treatment options at hand, including their advantages and disadvantages. Face-to-face diabetes education is one way to inform and empower patients. Research has shown the effects of diabetes education on relevant patient outcomes like knowledge, self-management behaviors, and glycemic control..$^{5-7}$ However, due to limited resources in health care, large numbers of patients still do not have access to feasible diabetes education. ${ }^{8-10}$ New forms of fostering patient involvement are needed to complement the established formats and to supply information at the time and pace that is suitable for the individual patient.

The Internet is widely regarded as an effective complementary source for addressing these topics. In times of rapidly growing Internet penetration, it holds the opportunity to deliver interactive, personalized, and individualized content to large numbers of users on comparatively low costs and at the time, place, and learning speed the individual user prefers. Consequently, people increasingly take advantage of these opportunities: The Pew Internet and American Life Project found that $51 \%$ of people living with one or more chronic conditions such as diabetes search the Internet for health information. The information they find there influences treatment decisions, coping, health behavior, and decisions on whether a health professional is consulted or not. ${ }^{11}$ However, the quality and usability of diabetes health information on the World Wide Web is limited - in their review, Thakurdesai et $\mathrm{al}^{12}$ found that quality, transparency, presentation, and broadness of content was deficient in the vast majority of the 53 diabetes patient education websites included in the study. Our own pilot study updates and corroborates this finding. Additionally, reading levels of patient materials on the web are often too high for the average user, not taking into account the great variance of health literacy in the population. ${ }^{13}$ Consequently, despite the abundance of information available on the web, patient materials might be inaccessible to users with lower health literacy.

Studies of systematically and thoroughly developed webbased health information show small but consistent effects on clinical outcomes, ${ }^{14-16}$ even in older populations that are often thought to use the web less frequently. ${ }^{17}$ Murray et al ${ }^{18}$ found that Interactive Health Communication Applications (IHCAs), a computer-based format combining health information with social support, decision support, or behavior change support, have positive effects on knowledge, social support, clinical, and behavioral outcomes. Still, the effectiveness of online applications is limited by high attrition rates, ${ }^{19-22}$ and few users visit a health intervention website more than once. ${ }^{23,24}$ Since the effect of online interventions increases with dose, 5,24 effectiveness is increased if users work intensively with the provided content ${ }^{21,25}$ and return for repeated visits. ${ }^{26,27}$ Several studies have reviewed strategies to enhance website usage. Individualization and personalization of information as well as an interactive presentation have been found to effectively reduce attrition rates and increase effectiveness of web-based interventions. ${ }^{28-30}$ These three strategies can be subsumed under the concept of tailoring. ${ }^{31}$ Tailoring information to individual needs and characteristics including different levels of health literacy has the potential to make health information accessible to a greater number of users.

The present work describes the development of a webbased tailored IHCA for patients with type 2 diabetes, offering diabetes information and support for medical decisions. The resulting IHCA is designed to improve user acceptance and adherence; it should increase the users' knowledge and empower them to be active partners in medical decisions and diabetes management. We are currently evaluating the IHCA in a randomized controlled trial. ${ }^{32}$ The primary hypothesis is that the tailored IHCA has larger effects on diabetes knowledge and patient empowerment (primary outcomes) than a standard website with identical content but without tailoring. Secondary outcomes are website usage as well as decisional conflict and preparation for decision making.

\section{Development work}

The basic assumptions were that the projected IHCA should be tailored, and that the content should comprise information, decision support, and behavior change support for people with type 2 diabetes. Consequently, three questions guided the planning of the IHCA: (1) Which content is relevant for the target group?, (2) How can the content be adequately tailored to the users' preferences?, and (3) Which technical design is feasible?

The result of the development process is an interactive educational intervention that contains general information on diabetes, information on health behavior and lifestyle changes, and treatment options. It incorporates educational, behavioral, and psychological intervention elements in our IHCA and combines didactic and interactive methods. This mix was found to have a greater effect on patient knowledge than interventions focusing on one aspect or method. ${ }^{5}$ 


\section{Content}

\section{Quality criteria for content}

Before the actual development work, we looked for a framework that could guide us through the process. There are international (Health On the Net code of conduct [HONcode], DISCERN) $)^{33,34}$ as well as German (Aktionsforum Gesundeitsinformationssystem [afgis] $)^{35}$ quality criteria for medical information on the Internet. These criteria can and did serve as an orientation during the content development but did not offer detailed advice on the process itself. A manual on the development process is provided by the German Agency for Quality in Medicine (ÄZQ). ${ }^{36}$ The manual on the development of evidence-based patient information ${ }^{36}$ that is offered on the ÄZQ's website is based on a checklist of quality criteria that was developed on the basis of DISCERN ${ }^{37}$ and Appraisal of Guidelines for Research and Evaluation (AGREE) $)^{38}$ (Table 1). The development process followed the steps proposed in this manual where appropriate. Whenever the advice did not match the project (eg, because of specifics of the Internet or because of financial restrictions), the primary author and editor of the manual was consulted.

\section{Needs assessment}

Since self-management education interventions that cover more than one diabetes-related topic produce larger effects than those focusing on one topic, ${ }^{5}$ the projected IHCA should include a variety of topics. In order to find out which topics are relevant to patients with type 2 diabetes, a needs assessment with two steps was performed. Firstly, semi-structured interviews with physicians and patients were conducted. Secondly, a selfassessment questionnaire for patients was developed, based on the main results of the interviews, which was administered to a larger patient sample. The questionnaire comprised four main sections: (1) health literacy and health locus of control; (2) Internet use and Internet experience; (3) relevant treatment decisions, decision preferences, and online health information needs; and (4) diabetes knowledge. The needs assessment and its results will be described in more detail elsewhere.

\section{Guidelines}

In order to ensure that the content is evidence-based, treatment guidelines were used as primary sources. For reasons of consistency only, guidelines that covered the whole range of diabetes management were included while guidelines that focused on distinguished aspects or sequelae of diabetes were excluded. In Germany, the development of such a comprehensive guideline was still underway when the information system was developed. Therefore, the British ${ }^{39}$ and the American ${ }^{40}$ guidelines were chosen as bases for the
Table I Quality criteria for patient health information

Scope and purpose

- Is the goal of the publication clearly defined?

- Is the target group of the publication clearly defined?

Stakeholder involvement

- Are the names of the authors stated?

- Are the qualifications of the authors stated?

- Is it stated whether patients or self-help organizations were involved in the development of the publication?

Accuracy

- Is it stated if the publication is based on scientific sources?

- Are the kinds of scientific sources stated?

- Is the date of creation stated?

- Is it stated how long the publication remains valid?

- Is a revision date stated?

- Is it stated whether the publication was developed following certain quality criteria (eg, DISCERN)?

- Is it stated whether the website holding the information participates in a quality initiative (eg, AFGIS, HON code, MedCIRCLE)?

- Does the publication contain sufficient information on additional information and literature?

- Are the modes of action of the medical procedures described sufficiently?

- Are the benefits of the medical procedures described sufficiently?

- Are potential risks of the medical procedures described sufficiently?

- Is it stated whether the medical procedures affect daily life?

- Is it stated whether there are contradicting results or experiences with respect to the medical procedures' effects and side effects?

- Is it explicitly stated whether all known medical procedures for the problem in question are named?

- Is the natural course of the condition (without treatment) described? Editorial independence

- Is the publication independent and unbiased?

Clarity of design

- Is it easy to identify the most important content?

- Is the content comprehensible?

Additional criteria for online health information

- Is it stated who operates the website?

- Is there a data security statement?

- Can the author and the webmaster be contacted directly?

- Is access unlimited?

- Can the content be printed in a single document?

Notes: Translated with permission from http://www.afgis. de/. ${ }^{35}$

Abbreviations: afgis, Aktionsforum Gesundeitsinformationssystem; HON, Health On the Net;

contents of the IHCA based on review articles, ${ }^{41,42}$ expert advice, and up-to-dateness. Their content was adapted to the German disease management program (DMP) with the help of German treatment professionals and researchers.

Based on the results of needs assessment and selected guidelines, a first draft of the content was created. The application comprises information on three main topics: what is type 2 diabetes?; how is it diagnosed?; and how is it treated? Information that is necessary to make the treatment decisions identified as relevant in the needs assessment includes the risks and benefits of the treatment options at hand (lifestyle, different 
forms of glucose monitoring, all oral medication that is available in Germany, different kinds of insulin and treatment regimens). Users are encouraged to write down their evaluations of the treatment options in question, as well as questions they might have, and discuss them with their doctors. Moreover, detailed risk information is given for various diabetes-related complications and common comorbidities (angiopathy, polyneuropathy, retinopathy, diabetic nephropathy, diabetic foot, depression, skin diseases, and sexual problems). Table 2 shows the subsections available within each of the main topics.

\section{Tailoring}

In a clinical consultation, the professional has the disease- and treatment-specific information and matches the information given and the way it is provided to the knowledge, interests, and other characteristics of the patient. The developed IHCA works accordingly, guiding the user through the information and selecting or modifying the information in a way that matches the individual patient. This corresponds to the concept of tailoring.

Kreuter et $\mathrm{al}^{31}$ define tailoring as 'any combination of strategies and information intended to reach one specific person,

Table 2 Overview of the IHCA's content

Chapters and sections

I. Introduction: What is this website?

I.I. Where does the information on this site come from?

2. Basics

2.I. Different diabetes types

2.2. How do I know I have type 2 diabetes?

2.3. What causes type 2 diabetes?

2.4. How many people live with type 2 diabetes?

2.5. How is type 2 diabetes diagnosed?

2.6. Diabetes $A B C s$

2.7. Blood sugar control

3. How is type 2 diabetes treated?

3.I. What are the goals of diabetes treatment?

3.2. What can you do to treat your diabetes?

3.3. When should you consider taking pills?

3.4. Insulin treatment

3.5. Summary and overview over the treatment options

4. Acute complications and sequelae

4.I. Which acute complications can occur?

4.2. Which sequelae can occur?

5. Additional information and literature

5.I. Associations and self-help

5.2. Websites

5.3. Journals

5.4. Books

6. Glossary

7. Legal notice

8. References

Notes: Modified from Weymann N, Harter M, Dirmaier J. A tailored, interactive health communication application for patients with type 2 diabetes: study protocol of a randomised controlled trial. BMC Med Inform Decis Mak. 20I3;13(I):24. ${ }^{32}$

Abbreviation: IHCA, Interactive Health Communication Application. based on characteristics that are unique to that person, related to the outcome of interest, and derived from an individual assessment' (p277). Individualized messages are supposed to be perceived as more relevant, interesting, and informative by the recipient. ${ }^{30}$ Results on the effectiveness of tailoring have been promising, but not consistently so. Some researchers have tried to identify key components that distinguish effective from less effective tailoring. ${ }^{43-45}$ Hawkins et al ${ }^{46}$ describe three key strategies for effective tailoring: personalization ("conveying that the communication is designed specifically for 'you"), feedback ("presenting patients with information about themselves'), and content matching ('forming messages according to the patient's status on determinants of the behavior of interest', eg, knowledge, attitudes/outcome expectancies). Further studies support the effectiveness of these three strategies. ${ }^{43,44}$

\section{Personalization}

Personalization is thought to enhance message processing by increasing attention and motivation. ${ }^{46}$ It can be realized by identifying the recipient by name ('identification') or by overtly claiming that the information offered is customized especially for the individual user ('raising expectation of customization'). This information can have a placebo effect even if there is no actual tailoring. ${ }^{47}$ Taking advantage of the placebo effect without fulfilling the promise of customization seems ethically questionable, but explicitly informing the user that tailoring is taking place seemed an appealing concept to us. A third personalization strategy is contextualization. Contextualization means framing information in a way that fits into the user's subjective reality (eg, starting from the user's attitude toward self-care when explaining the concept of self-care). In the tailored IHCA, the user is identified by his or her name, and the user is informed that the content is tailored to his or her individual characteristics. The personalized answers mirror what the user has said, convey esteem and empathy, and build an individualized bridge to the next content block. Whenever possible, content is contextualized according to the individual user's viewpoint (eg, 'As you said before ...'). These three personalization strategies are realized within a dialogue format (see ‘technical design').

\section{Feedback}

Feedback means presenting users with information about themselves. Besides increasing attention, feedback usually directly targets psychosocial determinants of the outcomes of interest. Hawkins et $\mathrm{al}^{46}$ described three forms of feedback: descriptive feedback ('reports what is known about the recipient based upon his or her data', p461), comparative feedback ('contrasts what is known about the recipient with 
what is known about others', p461), and evaluative feedback ('makes interpretations or judgments based on what is known about the recipient', p461). In the tailored IHCA, descriptive and evaluative feedback are performed. Feedback is given on the data the IHCA receives when the user answers questions on his or her diabetes knowledge, attitudes towards self-care, or hopes and fears related to insulin treatment. The IHCA mirrors the user's answers and provides tailored advice.

\section{Content matching}

Content matching, often thought of as the essence of tailoring, attempts to direct messages to individuals' status on key theoretical determinants (knowledge, outcome expectations, normative beliefs, efficacy and/or skills) of the behavior of interest (p462). ${ }^{46}$ Content matching on theoretical concepts such as attitudes was found to be especially effective. ${ }^{30}$ Content matching (as well as feedback) is performed on three determinants of successful self-management: health literacy, attitudes towards self-care, and barriers to insulin treatment ${ }^{48}$ were chosen as tailoring constructs.

The decision to tailor on health literacy was driven by the great variance of health literacy that was found in the needs assessment. Health literacy is operationalized by the user's pre-existing diabetes knowledge and the complexity of information he or she prefers. Knowledge tailoring is performed in two steps. Firstly, knowledge is assessed using a questionnaire based on the brief diabetes knowledge test. ${ }^{49}$ The original questionnaire was adapted to the text: one item on the pathophysiology of type 2 diabetes was added. Items were deleted for the following reasons: they aimed at messages that are not clearly evidence-based (one item); because they did not seem to fit German eating habits (two items); because the matching text passage was covered by self-care tailoring (two items); or because there were too many items for too short a text passage (three items). After each item, feedback is given on the result. If the answer was correct, this is reinforced, and the user can choose if he/she wants to learn more about the topic in question or proceed to the next content section. If the answer was wrong, the correct answer is explained and more information on the topic in question is provided before the user proceeds to the next content section. With respect to the complexity of information, all content that was identified as very important in the needs assessment was available in more or less detail, depending on the user's interest and ability. For each of these topics, the user can choose if he or she would like to have more detailed information or to move on to the next topic. Table 3 shows an example of knowledge tailoring.

Attitude toward self-care (diet, exercise, blood sugar testing, foot care, smoking) is assessed with a questionnaire that we developed based on the Summary of Diabetes Self Care Activities Questionnaire (SDSCA).${ }^{50}$ Motivation to perform the self-care activities is assessed on a 3-point Likert scale. Low motivation in self-care leads to answers that comply with the principles of motivational interviewing (expressing empathy, developing discrepancy, rolling with resistance, supporting self-efficacy). ${ }^{51}$ High motivation is reinforced and specific steps for action are proposed. Table 4 shows an example of self-care tailoring.

Psychological barriers to insulin treatment are assessed using the Barriers to Insulin Treatment Questionnaire (BIT). ${ }^{52}$ The BIT assesses the following expectations regarding insulin treatment: fear of injection and self-testing; expectations regarding positive insulin-related outcomes; expected hardship from insulin treatment; stigmatization by insulin injections; and fear of hypoglycemia. There are two or three items per subscale. In every item, a certain hope or fear with respect to insulin treatment is expressed (eg, 'I am afraid of the pain when injecting insulin.'). The user is asked to rate his or her agreement on a scale from 1 ('completely disagree') to 10 ('completely agree'). A score from 1 to 10 can be calculated for each subscale. A validating and understanding (if a fear was expressed) or reinforcing (if a hope was expressed) answer is given. If the score is over 1 , further information on the topic in question is provided. Table 5 shows an example of tailoring to psychological barriers to insulin treatment.

Table 3 Tailoring to knowledge on symptoms of hyperglycemia

\begin{tabular}{|c|c|c|c|}
\hline Item & \multicolumn{3}{|c|}{ If you feel thirsty and urinate frequently, it usually means your blood sugar is: } \\
\hline Response options & High (correct answer) & Low (wrong answer) & I don't know \\
\hline Reply & $\begin{array}{l}\text { That's correct! If you want to learn more } \\
\text { about what happens in the body and how } \\
\text { you know that you have type } 2 \text { diabetes, } \\
\text { you can go into more detail. Otherwise } \\
\text { you can proceed to the next question. } \\
\text { - l'd like to learn more about that topic. } \\
\text { - l'd like to proceed to the next question. }\end{array}$ & $\begin{array}{l}\text { No, that's not correct. Actually } \\
\text { it's the other way round: } \\
\text { When you have type } 2 \text { diabetes, } \\
\text { there is too much sugar in your blood. } \\
\text { Unfortunately, you don't realize it } \\
\text { in the beginning. But there are } \\
\text { warning signs. The most important } \\
\text { signs are [...] }\end{array}$ & $\begin{array}{l}\text { That's ok, [name], that's what we are } \\
\text { here for: to learn, for example, what } \\
\text { high blood sugar does to your body. } \\
\text { When you have type } 2 \text { diabetes, there } \\
\text { is too much sugar in your blood. } \\
\text { Unfortunately, you don't realize it in } \\
\text { the beginning. But there are warning } \\
\text { signs. The most important signs are [...] }\end{array}$ \\
\hline
\end{tabular}


Table 4 Tailoring to attitudes toward foot care

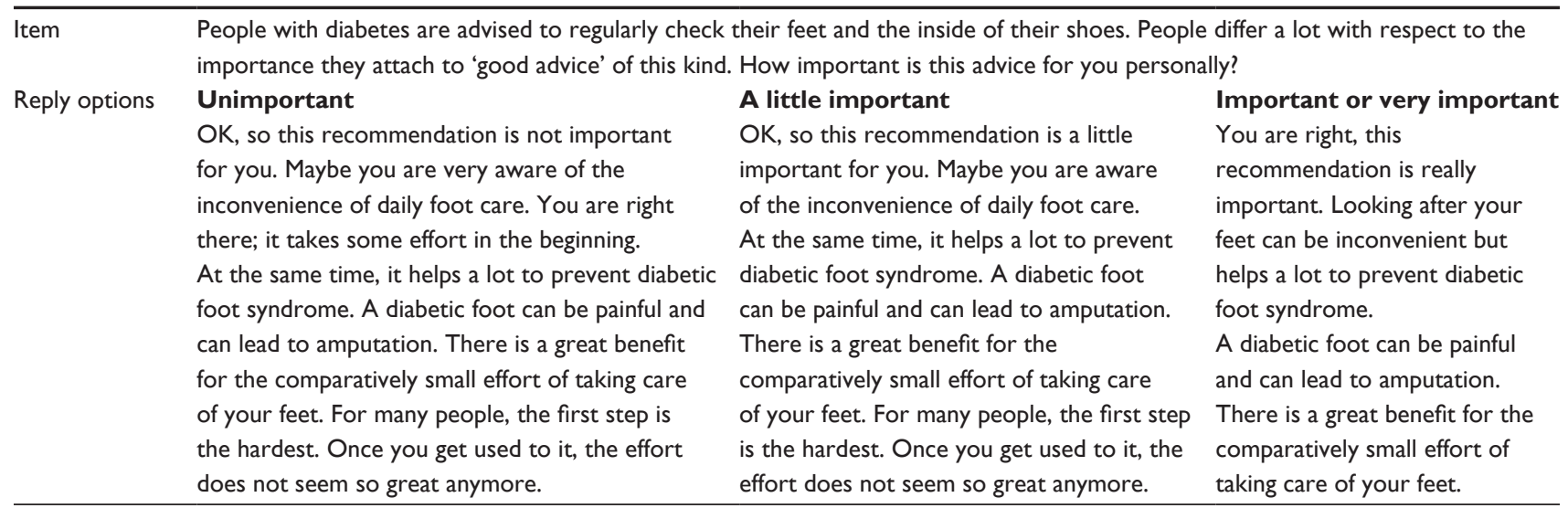

Notes: Modified from Weymann N, Harter M, Dirmaier J. A tailored, interactive health communication application for patients with type 2 diabetes: study protocol of a randomised controlled trial. BMC Med Inform Decis Mak. 20I3;I3(I):24. ${ }^{32}$

When a draft of the written content and the items and structure for tailoring were completed, they were sent to four experts from different related areas (internal medicine, diabetology, health education/medical journalism, and psycho-diabetology) who revised content and tailoring in an iterative process. They provided advice on correctness and completeness of the content, appropriateness with respect to the German health care system, comprehensible communication of complex and controversial medical issues, and psychosocial and motivational aspects. Special attention was given to appropriate reading levels of the texts.

\section{Technical design}

The system was developed in the format of a written dialogue, simulating a consultation or chat with a professional. The 'professional' or the tailored IHCA provides information or asks a question, the user replies, and the IHCA gives an answer that starts from what the user has said. For the user's side of the dialogue, three or more answers were created to every text passage that is provided by the IHCA. The user chooses one of the three options and receives a personalized answer. The technical design of the IHCA is tunneled in the sense that the user is guided through the content; the 'professional' has an agenda in mind of what might be helpful for the individual patient. Tunneled designs were found to increase website use and knowledge gained from a website when compared to a website without guidance. ${ }^{53}$ Even though being guided can be helpful when confronted with complex information, it can also annoy the user and evoke resistance; ${ }^{54}$ the patient might have an agenda on his or her own that differs from the professional's. The dialogue strikes a balance between guidance (suggestions made by the IHCA) and user control (reply options). This dialogue format has been found to be effective in depression and acute low back pain, ${ }^{5-58}$ but has not been applied to diabetes websites so far.

Table 5 Tailoring to an expressed fear of hypoglycemia

Items I. An overdose of insulin can lead to extremely low blood sugar (hypoglycemia). I am afraid of disagreeable symptoms.
Completely disagree
2. An overdose of insulin can lead to extremely low blood sugar (hypoglycemia). I am afraid of resulting health damages.
Completely disagree
I
Having slightly low blood sugar is hard to avoid when your blood sugar is in tight control. Usually, this can be handled easily. As long as
you reliably notice the first symptoms of such a slight hypoglycemia, it is no serious problem. They are an annoying but harmless side
effect of insulin treatment.
Most people with diabetes notice these warning signs very well, at the start of hypoglycemia so they can counteract them (eg, by taking
glucose). A minority of people with diabetes suffer from hypoglycemia unawareness. That means that you have difficulties noticing these
helpful warning signs. Mostly people who have been living with diabetes for a longer time suffer from hypoglycemia unawareness. There
are things you can do to improve hypoglycemia awareness, for example, by taking part in blood glucose awareness training.
If slight hypoglycemia occurs frequently or if you have severe hypoglycemia you should talk to your doctor about adapting your therapy.

Note: *The reply is given if a user reaches a sum score $>I$ in the two items. 
Programming and graphic design were performed by the Gaia AG (Hamburg, Germany), a subcontractor specializing in web-based health interventions. When content, structure, tailoring, and cornerstones of graphic design were completed by the research team and the advisory committee, they were handed over to the subcontractor for programming. Further elaboration of graphic design was coordinated in meetings between the research team and the subcontractor. A serious, medical style was agreed on. Labeled, partly interactive drawings were added to the complex content in order to make them more comprehensible ${ }^{59}$ and to enhance acceptance, especially in older users. ${ }^{60}$ Less complex text passages were complemented by photographs conveying positive affects in order to enhance recall of contents. ${ }^{61}$ When the first version of the IHCA was completed, it went through a phase of technical testing. Due to individualization, there are many paths that a user can take going through the system. Many of these paths were systematically tested by the subcontractor and the research team with respect to logic and functioning. Given the high complexity of the system, it was not possible to test all paths.

\section{Conclusion}

IHCAs that match the medical care situation can complement in-person education if patients have a high interest in and/or need for extensive or repeated information, live in underserved areas, and have access to the Internet. Practitioners might make use of IHCAs for eligible patients in order to improve diabetes knowledge and self-management. IHCAs are supposed to complement in-person counseling, and they work better for patients if they are combined with other forms of support; Brouwer et $\mathrm{al}^{28}$ found that peer support, counselor support, email, and phone contact increased exposure to web-based interventions. The integration of IHCAs into diabetes education could be especially effective if combined with the offer to discuss the content in telephone, chat, or in-person sessions. Offering IHCAs not only to patients but also to caregivers could be an asset both for the patients and for the caregivers. Studies show that caregivers search the web even more actively than the patients themselves. ${ }^{11,62}$ Another potential target group for the present IHCA are people at risk for developing type 2 diabetes. Current guidelines addressing the prevention of type 2 diabetes recommend similar behavioral changes regarding exercise, diet, and smoking cessation as presented in the IHCA. Target populations are people with impaired glucose tolerance, impaired fasting glucose, and/or metabolic syndrome. ${ }^{63-65}$
Web 2.0 features might further increase the attractiveness of IHCAs. According to the Pew Internet and American Life Project, ${ }^{11}$ Americans living with a chronic condition are more active members of the web community than healthy people. They use more social media, read user-generated content and generate content themselves, blog and chat about experiences with doctors, hospitals, medication, and/or offer emotional support. Inviting patients to share information and experience might enhance attractiveness and patient-centeredness of IHCAs. Other possible features would be online tracking of diet, blood sugar, or exercise, preferably with an app so that the patient can record his activities and blood sugar, and get the information they need in real-time. Finally, tailoring might become more effective if it was not static (assessed at only one point in time), but dynamically adapting to the user's present state. ${ }^{16}$ Further research and practical tests are needed to better understand how IHCAs can best support patients and professionals.

The opportunities created by technical progress can only be helpful to patients who know how to use them. This could be a challenge for older patients, while younger patients may take a liking to IHCAs and technical devices. While personal support and a good relationship between practitioners, patient, and caregivers is the basis for successful diabetes management, IHCAs could add new opportunities of education and self-management.

\section{Acknowledgments}

We would like to thank all patients and experts who were involved in the development of the IHCA. The experts who revised the IHCA's content and tailoring were: Felix Machleidt, MD (internal medicine and diabetology), Professor Ingrid Mühlhauser (health education and diabetology), Frank Petrak, PhD (psycho-diabetology), and Sylvia Sänger, $\mathrm{PhD}$ (health education and medical journalism). This study was funded by the German Federal Ministry of Education and Research, funding code 01GX0710.

\section{Disclosure}

The authors report no conflicts of interest in this work.

\section{References}

1. Deakin T, McShane CE, Cade JE, Williams RD. Group based training for self-management strategies in people with type 2 diabetes mellitus. Cochrane Database Syst Rev. 2005;(2):CD003417.

2. Wagner EH, Austin BT, Von Korff M. Organizing care for patients with chronic illness. Milbank Q. 1996;74(4):511-544.

3. Wagner EH, Austin BT, Davis C, Hindmarsh M, Schaefer J, Bonomi A Improving chronic illness care: translating evidence into action. Health Aff (Millwood). 2001;20(6):64-78. 
4. Charles C, Gafni A, Whelan T. Shared decision-making in the medical encounter: what does it mean? (or it takes at least two to tango). Soc Sci Med. 1997;44(5):681-692.

5. Fan L, Sidani S. Effectiveness of diabetes self-management education intervention elements: a meta-analysis. Can J Diabetes. 2009;33(1):18-26.

6. Ellis SE, Speroff T, Dittus RS, Brown A, Pichert JW, Elasy TA. Diabetes patient education: a meta-analysis and meta-regression. Patient Educ Couns. 2004;52(1):97-105.

7. Norris SL, Lau J, Smith SJ, Schmid CH, Engelgau MM. Self-management education for adults with type 2 diabetes: a meta-analysis of the effect on glycemic control. Diabetes Care. 2002;25(7):1159-1171.

8. Peyrot M, Rubin RR. Access to diabetes self-management education. Diabetes Educ. 2008;34(1):90-97.

9. Peyrot M, Rubin RR, Funnell MM, Siminerio LM. Access to diabetes self-management education: results of national surveys of patients, educators, and physicians. Diabetes Educ. 2009;35(2):246-248, 252-256, 258-263.

10. Shaw K, Killeen M, Sullivan E, Bowman P. Disparities in diabetes self-management education for uninsured and underinsured adults. Diabetes Educ. 2011;37(6):813-819.

11. Fox S, Purcell K. Chronic Disease and the Internet. An initiative of the Pew Research Center; 2010. Washington DC: Pew Internet and American Life Project. Available from: http://pewinternet.org/ Reports/2010/Chronic-Disease.aspx. Accessed January 9, 2012.

12. Thakurdesai PA, Kole PL, Pareek RP. Evaluation of the quality and contents of diabetes mellitus patient education on Internet. Patient Educ Couns. 2004;53(3):309-313.

13. Stossel LM, Segar N, Gliatto P, Fallar R, Karani R. Readability of patient education materials available at the point of care. J Gen Intern Med. 2012;27(9):1165-1170.

14. Samoocha D, Bruinvels DJ, Elbers NA, Anema JR, van der Beek AJ. Effectiveness of web-based interventions on patient empowerment: a systematic review and meta-analysis. J Med Internet Res. 2010; 12(2):e23.

15. Roshanov PS, Misra S, Gerstein HC, et al. Computerized clinical decision support systems for chronic disease management: a decisionmaker-researcher partnership systematic review. Implement Sci. 2011;6:92.

16. Krebs P, Prochaska JO, Rossi JS. A meta-analysis of computer-tailored interventions for health behavior change. Prev Med. 2010;51(3-4): 214-221.

17. Bond GE, Burr RL, Wolf FM, Feldt K. The effects of a web-based intervention on psychosocial well-being among adults aged 60 and older with diabetes: a randomized trial. Diabetes Educ. 2010;36(3):446-456.

18. Murray E, Burns J, See Tai S, Lai R, Nazareth I. Interactive Health Communication Applications for people with chronic disease. Cochrane Database Syst Rev. 2005;(4):CD004274.

19. Leslie E, Marshall AL, Owen N, Bauman A. Engagement and retention of participants in a physical activity website. Prev Med. 2005;40(1):54-59.

20. Glasgow RE. eHealth Evaluation and Dissemination Research. Am J Prev Med. 2007;32(Suppl 5):S119-S126.

21. Eysenbach G. The law of attrition. J Med Internet Res. 2005;7(1):e11.

22. Cook C, Heath F, Thompson R. A meta-analysis of response rates in web- or Internet-based surveys. Educ Psychol Meas. 2000;60:20-24.

23. Brouwer W, Oenema A, Raat H, et al. Characteristics of visitors and revisitors to an Internet-delivered computer-tailored lifestyle intervention implemented for use by the general public. Health Educ Res. 2010;25(4):585-595.

24. Verheijden MW, Jans MP, Hildebrandt VH, Hopman-Rock M. Rates and determinants of repeated participation in a web-based behavior change program for healthy body weight and healthy lifestyle. $J \mathrm{Med}$ Internet Res. 2007;9(1):e1.

25. Danaher BG, Boles SM, Akers L, Gordon JS, Severson HH. Defining participant exposure measures in Web-based health behavior change programs. J Med Internet Res. 2006;8(3):e15.
26. Christensen H, Griffiths KM, Farrer L. Adherence in internet interventions for anxiety and depression. J Med Internet Res. 2009;11(2):e13.

27. Norman GJ, Zabinski MF, Adams MA, Rosenberg DE, Yaroch AL, Atienza AA. A review of eHealth interventions for physical activity and dietary behavior change. Am J Prev Med. 2007;33(4):336-345.

28. Brouwer W, Kroeze W, Crutzen R, et al. Which intervention characteristics are related to more exposure to internet-delivered healthy lifestyle promotion interventions? A systematic review. J Med Internet Res. 2011;13(1):e2.

29. Boudreau F, Godin G, Poirier P. Effectiveness of a computer-tailored print-based physical activity intervention among French Canadians with type 2 diabetes in a real-life setting. Health Educ Res. 2011;26(4): 573-585.

30. Noar SM, Benac CN, Harris MS. Does tailoring matter? Meta-analytic review of tailored print health behavior change interventions. Psychol Bull. 2007;133(4):673-693.

31. Kreuter M. Tailoring Health Messages: Customizing Communication with Computer Technology. Mahwah, NJ: Erlbaum; 2000.

32. Weymann N, Harter M, Dirmaier J. A tailored, interactive health communication application for patients with type 2 diabetes: study protocol of a randomised controlled trial. BMC Med Inform Decis Mak. 2013;13(1):24.

33. The Health on the Net Foundation Code of Conduct (HONcode). Available from: http://www.healthonnet.org/HONcode/. Accessed January 9, 2012.

34. DISCERN. Quality criteria for consumer health information. Available from: http://www.discern.org.uk. Accessed January 9, 2012.

35. Aktionsforum Gesundheitsinformationssystem (afgis) e.V. Available from: http://www.afgis.de/standards/afgis-checkliste-medizinischewebsite-version-1.0-maerz-2010. Accessed January 9, 2013. German.

36. Sänger S, Lang B, Klemperer D. Manual Patienteninformation. Empfehlungen zur Erstellung evidenzbasierter Patienteninformationen. äzq Schriftenreihe 25. [Manual of patient information. Recommendations for the creation of evidence-based patient information. AQuMed Series 25]. Berlin: Ärztliches Zentrum für Qualität in der Medizin. [Agency for Quality in Medicine]; 2006.

37. Charnock D, Shepperd S, Needham G, Gann R. DISCERN: an instrument for judging the quality of written consumer health information on treatment choices. J Epidemiol Community Health. 1999;53(2): 105-111.

38. The AGREE Collaboration. Appraisal of Guidelines for Research and Evaluation. AGREE Instrument. 2001. Available at: http://www. agreetrust.org. Accessed January 9, 2013.

39. National Institute for Health and Clinical Excellence (NICE). National Guideline C. Type 2 diabetes. The management of type 2 diabetes. Agency for Healthcare Research and Quality (AHRQ). Available at: http://www. guideline.gov/content.aspx?id=15202. Accessed December 14, 2012.

40. American Diabetes Association. Standards of medical care in diabetes-2010. Diabetes Care. 2010;33(Suppl 1):S11-S61.

41. Burgers JS, Bailey JV, Klazinga NS, Van Der Bij AK, Grol R, Feder G. Inside guidelines: comparative analysis of recommendations and evidence in diabetes guidelines from 13 countries. Diabetes Care. 2002;25(11):1933-1939.

42. Stone MA, Wilkinson JC, Charpentier G, et al. Evaluation and comparison of guidelines for the management of people with type 2 diabetes from eight European countries. Diabetes Res Clin Pract. 2010; 87(2):252-260.

43. Lustria ML, Cortese J, Noar SM, Glueckauf RL. Computer-tailored health interventions delivered over the Web: review and analysis of key components. Patient Educ Couns. 2009;74(2):156-173.

44. Dijkstra A. Working mechanisms of computer-tailored health education: evidence from smoking cessation. Health Education Research. 2005;20(5):527-539.

45. Williams DM, Papandonatos GD, Jennings EG, et al. Does tailoring on additional theoretical constructs enhance the efficacy of a print-based physical activity promotion intervention? Health Psychol. 2011;30(4): $432-441$. 
46. Hawkins RP, Kreuter M, Resnicow K, Fishbein M, Dijkstra A. Understanding tailoring in communicating about health. Health Educ Res. 2008;23(3):454-466.

47. Webb MS, Simmons VN, Brandon TH. Tailored interventions for motivating smoking cessation: using placebo tailoring to examine the influence of expectancies and personalization. Health Psychol. 2005;24(2):179-188.

48. Polonsky WH, Fisher L, Guzman S, Villa-Caballero L, Edelman SV. Psychological insulin resistance in patients with type 2 diabetes: the scope of the problem. Diabetes Care. 2005;28(10):2543-2545.

49. Fitzgerald JT, Funnell MM, Hess GE, et al. The reliability and validity of a brief diabetes knowledge test. Diabetes Care. 1998;21(5):706-710.

50. Toobert DJ, Hampson SE, Glasgow RE. The summary of diabetes self-care activities measure: results from 7 studies and a revised scale. Diabetes Care. 2000;23(7):943-950.

51. Miller WR, Rollnick S. Motivational Interviewing, Second Edition: Preparing People for Change. New York: Guilford Press; 2002.

52. Petrak F, Stridde E, Leverkus F, Crispin AA, Forst T, Pfutzner A. Development and validation of a new measure to evaluate psychological resistance to insulin treatment. Diabetes Care. 2007;30(9):2199-2204.

53. Crutzen R, Cyr D, de Vries NK. The role of user control in adherence to and knowledge gained from a website: randomized comparison between a tunneled version and a freedom-of-choice version. $J \mathrm{Med}$ Internet Res. 2012;14(2):e45.

54. Danaher BG, McKay HG, Seeley JR. The information architecture of behavior change websites. J Med Internet Res. 2005;7(2):e12.

55. Meyer B, Berger T, Caspar F, Beevers GC, Andersson G, Weiss M. Effectiveness of a novel integrative online treatment for depression (Deprexis): randomized controlled trial. J Med Internet Res. 2009;11(2):e15.

56. Simon D, Kriston L, von Wolff A, et al. Effectiveness of a web-based, individually tailored decision aid for depression or acute low back pain: a randomized controlled trial. Patient Educ Couns. 2012;87(3): 360-368.
57. Moritz S, Schilling L, Hauschildt M, Schroder J, Treszl A. A randomized controlled trial of internet-based therapy in depression. Behav Res Ther. 2012;50(7-8):513-521.

58. Cuijpers P, Donker T, Johansson R, Mohr DC, van Straten A, Andersson G. Self-guided psychological treatment for depressive symptoms: a meta-analysis. PloS one. 2011;6(6):e21274.

59. Rosen D, Purinton E. Website design: viewing the web as a cognitive landscape. J Bus Res. 2004;57:787-794.

60. van Weert JC, van Noort G, Bol N, van Dijk L, Tates K, Jansen J. Tailored information for cancer patients on the Internet: effects of visual cues and language complexity on information recall and satisfaction. Patient Educ Couns. 2011;84(3):368-378.

61. Monahan JL. Thinking positively: using positive affect when designing healt messages. In: Maibach EW, Parrot RL, editors. Designing Health Messages: Approaches from Communication Theory and Public Health Practice. Thousand Oaks, CA: Sage; 1995:81-98.

62. Ybarra ML, Suman M. Help seeking behavior and the Internet: a national survey. Int J Med Inform. 2006;75(1):29-41.

63. Paulweber B, Valensi P, Lindstrom J, et al. A European evidence-based guideline for the prevention of type 2 diabetes. Horm Metab Res. 2010;42 Suppl 1:S3-S36.

64. Lindstrom J, Neumann A, Sheppard KE, et al. Take action to prevent diabetes - the IMAGE toolkit for the prevention of type 2 diabetes in Europe. Horm Metab Res. 2010;42(Suppl 1):S37-S55.

65. Greaves CJ, Sheppard KE, Abraham C, et al. Systematic review of reviews of intervention components associated with increased effectiveness in dietary and physical activity interventions. BMC Public Health. 2011;11:119.
Patient Preference and Adherence

\section{Publish your work in this journal}

Patient Preference and Adherence is an international, peer-reviewed, open access journal focusing on the growing importance of patient preference and adherence throughout the therapeutic continuum. Patient satisfaction, acceptability, quality of life, compliance, persistence and their role in developing new therapeutic modalities and compounds to

\section{Dovepress}

optimize clinical outcomes for existing disease states are major areas of interest. This journal has been accepted for indexing on PubMed Central. The manuscript management system is completely online and includes a very quick and fair peer-review system. Visit http://www.dovepress.com/ testimonials.php to read real quotes from published authors. 